(c) American Dairy Science Association, 2007.

\title{
Voluntary Waiting Period and Adoption of Synchronized Breeding in Dairy Herd Improvement Herds
}

\author{
R. H. Miller, ${ }^{\star 1}$ H. D. Norman, ${ }^{\star}$ M. T. Kuhn, ${ }^{\star}$ J. S. Clay,† and J. L. Hutchison* \\ *Animal Improvement Programs Laboratory, Agricultural Research Service, USDA, Beltsville, MD 20705-2350 \\ †Dairy Records Management Systems, Raleigh, NC 27603
}

\begin{abstract}
Voluntary waiting period and adoption of synchronized breeding (ovulation synchronization followed by timed artificial insemination) were characterized from 33 million services of Holsteins and Jerseys in Dairy Herd Improvement herds. Calving month, calving year, and parity had large effects on days to first service for both breeds. Holstein cows that calved during March and April were bred later than those that calved during other months (February and March for Jerseys), whereas cows that calved during September and October were bred earlier. First-parity cows had longer days to first service than did second-parity cows. Herdyear voluntary waiting period was measured as the days postpartum by which $10 \%$ of cows had received a first insemination. Median days to reach $10 \%$ of cows bred were $55.5 \mathrm{~d}$. Over $65 \%$ of herds had $10 \%$ of cows inseminated by $60 \mathrm{~d}$ postpartum, the voluntary waiting period assumed for national evaluations for daughter pregnancy rate. Herd-years with synchronized breeding at first insemination were identified through $\chi^{2}$ analysis based on deviation of observed frequency of first inseminations by day of the week from an expected equal frequency and by the maximum percentage of cows inseminated on a particular day of the week. Herds that were identified as having synchronized breeding had fewer days to first service (17.0), more services (0.16/cow), and fewer days open (9.1) than did herds that were classified as having traditional estrus detection. Synchronized herds also had a standard deviation for days to first service that was only $38 \%$ as large as that for herds that bred on observed estrus. Adoption of synchronized breeding for first services steadily increased from $1.9 \%$ of herdyears (2\% of cows) for 1996 to $19.9 \%$ of herd-years (34.9\% of cows) for 2005. Procedures for genetic evaluation of daughter pregnancy rate should be examined to determine if herd regimen for reproductive management affects results.
\end{abstract}

Received December 28, 2005.

Accepted November 2, 2006.

${ }^{1}$ Corresponding author: millerrh@juno.com
Key words: voluntary waiting period, days to first service, synchronization, timed artificial insemination

\section{INTRODUCTION}

Voluntary waiting period (VWP) is a key management decision in which the herd manager designates a target number of days postpartum after which cows will be inseminated. The interval from calving to first insemination provides time for uterine involution. Within a herd, the VWP may be flexible (e.g., cows that were observed in estrus a few days before a fixed VWP might be inseminated before the target date). Also, some herds may have variable VWP (e.g., longer for high producers or for first-parity cows). A VWP of $60 \mathrm{~d}$ is assumed for calculating national genetic evaluations for daughter pregnancy rate (VanRaden et al., 2004).

One factor in choosing a VWP for lactating cows is that conception rate is expected to increase as days postpartum increase (Britt, 1975; Tenhagen et al., 2003 ), which may be partly related to milk yield. Washburn et al. (2002) reported that days to first service (DFS) after calving have increased over time in southeastern US herds. Faust et al. (1988) found that milk yield negatively affects conception rate. Some researchers have hypothesized that this antagonism is related to negative energy balance or body condition during early lactation (Britt, 1975; Moreira et al., 2000 ) or to impaired expression of estrus (Harrison et al., 1990). Tenhagen et al. (2001, 2003), however, found no effect of level of milk yield on conception rate after timed AI (TAI).

Reducing VWP is tempting because of associated reductions in calving interval. Williamson et al. (1980) reported that a 1-d reduction in DFS decreased calving interval by $0.86 \mathrm{~d}$. Linderoth (2005), however, recommended a VWP of $>60 \mathrm{~d}$ because 20 to $30 \%$ of cows were anovulatory at $60 \mathrm{~d}$. Cows that conceive too early during lactation may need to be dried off when milk yield is still relatively high (Britt, 1975; Plunkett et al., 1984; Linderoth, 2005). Olson (2004) discussed choosing a VWP relative to parity and noted a trend for greater lactation persistency for first-parity cows 
and a need for longer dry periods. Weller and Folman (1990) suggested that an economically optimum VWP is at least 2 wk longer for first parity than for second. Tenhagen et al. (2003) advocated a VWP of $>73 \mathrm{~d}$ for TAI regimens.

Various protocols to synchronize estrus or ovulation among cows have been investigated. Pursley et al. (1995) developed a method of synchronized ovulation by administering $\mathrm{GnRH}$ at a random stage of the estrous cycle, $\mathrm{PGF}_{2 \alpha} 7 \mathrm{~d}$ later, and $\mathrm{GnRH}$ again $48 \mathrm{~h}$ after $\mathrm{PGF}_{2 \alpha}$. A TAI was given to all cows 20 to $24 \mathrm{~h}$ after the second GnRH injection. Subsequently, Pursley et al. $(1997 \mathrm{a}, \mathrm{b})$ compared the effectiveness of this protocol (Ovsynch) with traditional reproductive management (daily detection of estrus, a.m.-p.m. breeding rule, and occasional use of $\mathrm{PGF}_{2 \alpha}$ or $\mathrm{GnRH}$ ); a VWP of $50 \mathrm{~d}$ was chosen. Median days open and DFS were fewer for treated than for control cows; pregnancy rate for first AI service was similar for treated and control cows. Rabiee et al. (2005) presented a meta-analysis review of results from 53 published reports on the Ovsynch protocol as well as other synchrony programs such as $\mathrm{PGF}_{2 \alpha}$ injections, Heat Synch, Select Synch, and modified Ovsynch. They concluded that conception and pregnancy rates from first inseminations with the various modified synchronization protocols were comparable with those from Ovsynch. Because all cows received first inseminations at a predetermined time, however, the Ovsynch-treated cows had much greater pregnancy rates at first insemination than did cows inseminated after observed estrus.

Tenhagen et al. (2003) evaluated the effects of lactation stage and level of milk yield on conception rates and pregnancy rates of 1,288 German Holsteins in which ovulation was synchronized with the Ovsynch protocol. For cows with similar yield, first-service conception rates were less for cows synchronized earlier during lactation than for those synchronized later. Level of milk yield had no effect on conception rates after TAI in cows synchronized at similar DIM. At 200 DIM, fewer high-yielding cows were pregnant than cows with mean or low production, regardless of DIM when ovulation was synchronized. Subsequently, Tenhagen et al. (2004) compared a synchronized breeding protocol with traditional AI administered after detected estrus in 2 German commercial dairy herds. Ovsynch reduced interval to first service after calving and days open in both herds and reduced culling for infertility in the herd with poorer rates of detected estrus. Conception rate at first service, however, was greater for those cows inseminated after detected estrus than for those receiving TAI in both herds. Tenhagen et al. (2004) concluded that synchronized breeding is more beneficial for herds with poor detection of es- trus. Goodling et al. (2005) found that days open for herds with timed insemination were $17 \mathrm{~d}$ fewer than for herds with insemination after observed estrus.

Various strategies can be used to synchronize breeding (Stevenson and Phatak, 2005). Stevenson (2004, 2005) suggested that first service after calving could be based on customary AI after detected estrus and then an Ovsynch protocol could be applied to cows diagnosed open for subsequent $\mathrm{AI}$ services and also restated the importance of detection of estrus.

Research is needed to determine whether genetic evaluation procedures for daughter pregnancy rate need to be modified to account for reproductive-management regimen. Goodling et al. (2005) studied 64 progeny-test herds that were using a variety of reproductive-management regimens. Synchronized breeding did not affect heritability of DFS, days open, or pregnancy rate at $120 \mathrm{~d}$. Goodling et al. (2005) recommended investigating a possible interaction between sire and management regimen and adjusting genetic evaluations for heterogeneous variance. Data submitted to USDA to calculate national evaluations for daughter pregnancy rate have no designation for the type of herd reproductive-management regimen (VanRaden et al., 2004). Identification of herds that definitely practice synchronization and those that definitely use traditional estrus-detection programs would be useful.

Objectives of this study were to 1) document variation in DFS, 2) determine consistency of herd VWP over time, 3) investigate possible criteria for identifying herds with synchronized breeding regimens (ovulation synchronization followed by TAI) for first inseminations, 4) characterize use of synchronized breeding over time, and 5) determine differences in DFS and days open between herds with traditional estrus-detection programs and those with synchronized breeding.

\section{MATERIALS AND METHODS}

\section{Data}

Data were records for 33 million Holstein and Jersey inseminations in DHI herds from 1995 through 2005 that included calving date, service date, and service sire. Data were primarily from Dairy Records Management Systems (Raleigh, NC, and Ames, IA) and AgSource (Verona, WI). Herd-years with $<30$ first services were excluded; 136,691 herd-years remained for analysis of first inseminations.

\section{Variation in DFS and VWP}

Least squares analyses of DFS were conducted separately for Holsteins and Jerseys. The model included 
fixed effects for herd, calving year, calving month, and parity. Cows without a first-lactation record in the data set were not included.

To evaluate variation in VWP, 84,578 herd-year means from 1995 through 2005 were calculated. For each herd-year, the cumulative frequency distribution was recorded for 9 postpartum intervals for DFS: $\leq 30$, $\leq 40, \leq 50, \leq 60, \leq 70, \leq 90, \leq 120, \leq 150$, and $\leq 200 \mathrm{~d}$. Because herd VWP was not available, herd VWP was defined as the days postpartum by which $10 \%$ of cows in the herd-year had received a first insemination (S. Eicker, Valley Agricultural Software, Tulare, CA; personal communication).

\section{Identification of Herds with Synchronized Breeding}

The premise in developing methods to detect synchronization was that herds using synchronization would have an unequal distribution of inseminations across days of the week, whereas inseminations for nonsynchronized herds would occur equally frequently across weekdays. For example, a synchronizing herd might have $70 \%$ of its breedings on Thursdays, whereas a nonsynchronized herd would be expected to have about $14 \%(1 / 7)$ of its inseminations on each day of the week. Large deviations from the expected frequency would be an indication that the herd had synchronized inseminations.

A preliminary study by Miller et al. (2005) used a $\chi^{2}$ method to detect herds with synchronized breeding based on a comparison of observed frequencies of first inseminations by day of the week with an expected equal frequency among days. The magnitude of the resulting $\chi^{2}$ was used to determine the likelihood of synchronized breeding. The $\chi^{2}$ values, however, are greatly dependent on herd size; for a similar distribution of inseminations on a given day, a 1,000-cow herd might have a $\chi^{2}$ value of 2,500 , whereas a 50 -cow herd would have a $\chi^{2}$ value of only 130 . Although the method of Miller et al. (2005) seemed to be reliable for large herds, it was less useful for small herds.

Simulation studies (see Appendix) were used to investigate 2 statistics for their effectiveness in identifying unequal distributions of first inseminations among days of the week: maximum percentage of first inseminations on $1 \mathrm{~d}$ of the week $\left(\%_{\max }\right)$ and mean $\chi^{2}$ adjusted for herd size $\left(\bar{\chi}_{h}^{2}\right)$. The $\bar{\chi}_{h}^{2}$ was computed as:

$$
\left[\Sigma\left(\left[N_{i}-\left(\Sigma N_{i} / 7\right)\right]^{2} /\left(\Sigma N_{i} / 7\right)\right) / \Sigma N_{i}\right] \times 100,
$$

where $N_{i}$ is the number of first inseminations observed on week day $i\left(i=1\right.$ to 7 ), $\Sigma N_{i} / 7$ is the expected number of first inseminations on any given day under the null hypothesis of an equal number of first inseminations per day, $\Sigma N_{i}$ is the total number of first inseminations for a given herd-year (i.e., herd size), and 100 is a scaling factor.

As an example, consider a 200-cow herd with 8 first inseminations on Sundays, 14 on Mondays, 22 on Tuesdays, 120 on Wednesdays, 20 on Thursdays, 10 on Fridays, and 6 on Saturdays. The $\%_{\max }$ for that herd would be $100 \times 120 / 200$ or $60 \%$. If the herd did not have synchronized breeding, the expected number of first inseminations on each day $\left(\Sigma N_{i} / 7\right)$ would be $200 / 7$ or 28.6 . The $\bar{\chi}_{h}^{2}$ would be $\left[(8-28.6)^{2} / 28.6+(14\right.$ $-28.6)^{2} / 28.6+(22-28.6)^{2} / 28.6+(120-28.6)^{2} / 28.6+$ $\left.(20-28.6)^{2} / 28.6+(10-28.6)^{2} / 28.6+(6-28.6)^{2} / 28.6\right] /$ $200 \times 100$, or 174 .

Based on results of simulation studies of statistic effectiveness for identifying herds with synchronized breeding (see Appendix), herds were classified as having synchronized breeding if $\%_{\max }$ was $>35 \%$ without regard to herd size and if $\bar{\chi}_{h}^{2}$ was $>45$ for herds with $<50$ first inseminations or $>40$ for herds with $\geq 50$ first inseminations. Other herds were considered not to have synchronized breeding. Herds with $<30$ first inseminations were not analyzed. Herds that were identified as having synchronized breeding were then subdivided based on the likelihood of synchronization: possible $\left(\bar{\chi}_{h}^{2}<84\right)$, probable $\left(84 \geq \bar{\chi}_{h}^{2} \leq 400\right)$, and synchronized $\left(\bar{\chi}_{h}^{2}>400\right)$. Table 1 shows example statistics from a randomly chosen herd from each of the 4 likelihood categories for synchronized breeding.

Days-open data from matching lactations were extracted from the national database at the Animal Improvement Programs Laboratory (Beltsville, MD). Herd-year means for DFS, number of services, and days open were compared for the 4 synchronization categories. A least squares analysis of herd-year means was performed with the effects of herd and synchronization status included; thus, only herds that changed synchronization status contributed to the estimates of category differences.

\section{RESULTS AND DISCUSSION}

\section{Variation in DFS}

For DFS ANOVA (Table 2), all model effects were significant $(P<0.01)$. All effects for Jerseys, however, were much smaller than corresponding results for Holsteins. Effect of calving month on DFS was large for Holsteins, but smaller for Jerseys.

Least squares estimates of the difference in DFS among calving years (Figure 1) were much larger for Holsteins (range of $6.5 \mathrm{~d}$ ) than for Jerseys (range of 
Table 1. Maximum percentage of first inseminations on $1 \mathrm{~d}$ of the week $\left(\%_{\max }\right)$, mean $\chi^{2}$ adjusted for herd size $\left(\bar{\chi}_{h}^{2}\right)$, and number of first inseminations by day of the week for a randomly chosen herd from each of 4 groups used to identify herd status for synchronized breeding (ovulation synchronization followed by timed AI)

\begin{tabular}{|c|c|c|c|c|c|c|c|c|c|c|}
\hline \multirow{2}{*}{$\begin{array}{l}\text { Herd status } \\
\text { for synchronized } \\
\text { breeding }\end{array}$} & \multirow{2}{*}{$\begin{array}{c}\text { Cows, } \\
\text { no. }\end{array}$} & \multirow[b]{2}{*}{$\%_{\max }$} & \multirow[b]{2}{*}{$\bar{\chi}_{h}^{2}$} & \multicolumn{7}{|c|}{ First inseminations, no. } \\
\hline & & & & Sun & Mon & Tue & Wed & Thu & Fri & Sat \\
\hline None & 36 & 28 & 21.0 & 3 & 5 & 3 & 10 & 6 & 3 & 6 \\
\hline Possible & 48 & 38 & 49.5 & 5 & 18 & 7 & 2 & 4 & 7 & 5 \\
\hline Probable & 70 & 46 & 100.0 & 1 & 9 & 9 & 32 & 14 & 4 & 1 \\
\hline Synchronized & 150 & 91 & 485.4 & 2 & 137 & 5 & 0 & 1 & 1 & 4 \\
\hline
\end{tabular}

3.2 d). Peak DFS was in 1996 for Holsteins and in 2000 for Jerseys.

Least squares estimates of the difference in DFS among calving months are shown in Figure 2. Holstein cows that calved during March and April were bred later $(P<0.01)$ during lactation than were cows that calved during other months (6.2 to $6.4 \mathrm{~d}$ later than December calvings). Jersey cows calving in March were bred $4.8 \mathrm{~d}$ later $(P<0.01)$ than December calvings. In many regions, some spring calvers may not be bred during hot summer months, although those cows may qualify for insemination based on VWP criteria. Cows that calved during September and October were bred the earliest $(P<0.01 ; 2.0$ to $2.1 \mathrm{~d}$ earlier than December calvings for Holsteins and 3.7 to $4.2 \mathrm{~d}$ for Jerseys). Differences in DFS among calving months were slightly larger for Jerseys (range of $9.0 \mathrm{~d}$ ) than for Holsteins (range of $8.5 \mathrm{~d}$ ).

Least squares estimates of the difference in DFS among parities (Figure 3) were smaller (range of 5.7 $\mathrm{d}$ for Holsteins and $4.6 \mathrm{~d}$ for Jerseys) than those for calving season. For both breeds, first-parity cows were bred later than second-parity cows. The difference was larger for Jerseys ( $3.7 \mathrm{~d}$ ), however, than for Holsteins $(2.1 \mathrm{~d})$. The insemination of first-parity cows by 2 to $4 \mathrm{~d}$ later than for second-parity cows was much smaller than the optimum of 18 to $25 \mathrm{~d}$ advocated by Weller and Folman (1990) for Israeli Holsteins. After second parity, Holsteins were bred progressively later for successive parities. Third-parity Jerseys were bred at the

Table 2. $F$-values from ANOVA of days to first service after calving

\begin{tabular}{lcc}
\hline Effect $^{1}$ & $\begin{array}{c}\text { Holstein } \\
\text { (error df }=5,415,468)\end{array}$ & $\begin{array}{c}\text { Jersey } \\
(\text { error } \mathrm{df}=281,055)\end{array}$ \\
\hline Calving year & 1,099 & 15 \\
Calving month & 3,120 & 163 \\
Parity & 621 & 112 \\
\hline
\end{tabular}

${ }^{1}$ All effects significant at $P<0.01$. same stage as second parity and then progressively later for subsequent parities. The DFS differences were estimated across all herds; subsets of herds with various VWP policies might exhibit patterns that were more similar to those suggested as optimal by Weller and Folman (1990). Therefore, to determine if adoption of synchronized breeding affected variation in DFS, within-herd standard deviations were calculated by calving year (Figure 4). Although no linear trend was found, the variation of DFS for Holsteins has declined; variation was largest in 1996 for both breeds and smallest in 2004 for Holsteins and in 2001 for Jerseys. Adoption of synchronized breeding may have reduced variation in DFS over time.

\section{Consistency of Herd VWP}

The basic measure to assess VWP was DFS. Median DFS was 92, 97, 94, 93, 90, 93, 87, 91, 90, and 90 for service years 1996 through 2005, respectively. Figure 1 shows a decline of $6.5 \mathrm{~d}$ in DFS for Holstein calving years from 1996 to 2004, which is consistent with the increase in the national means for Holstein pregnancy rate from $22.4 \%$ for cows born in 1995 to $23.6 \%$ for cows born in 2003 (Animal Improvement Programs Laboratory, 2006), a change equivalent to a decrease of $4.8 \mathrm{~d}$ open. Annual changes were much smaller for Jerseys; they peaked between 1998 and 2000 at 1.7 to $2.4 \mathrm{~d}$.

Table 3 shows change in VWP over time, with VWP defined as the days postpartum at which $10 \%$ of cows in the herd-year had been first inseminated. By $60 \mathrm{~d}$ postpartum, the percentage of herd-years with $10 \%$ of cows that had received first services decreased $(P<$ 0.01) from 74 in 1995 to 66 in 2005. Differences among years within days postpartum, however, were not significant $(P \geq 0.05)$. Corresponding percentages by 50 $\mathrm{d}$ postpartum were 28 and 25 . The 60 -d VWP assumed by USDA for calculating genetic evaluations for 


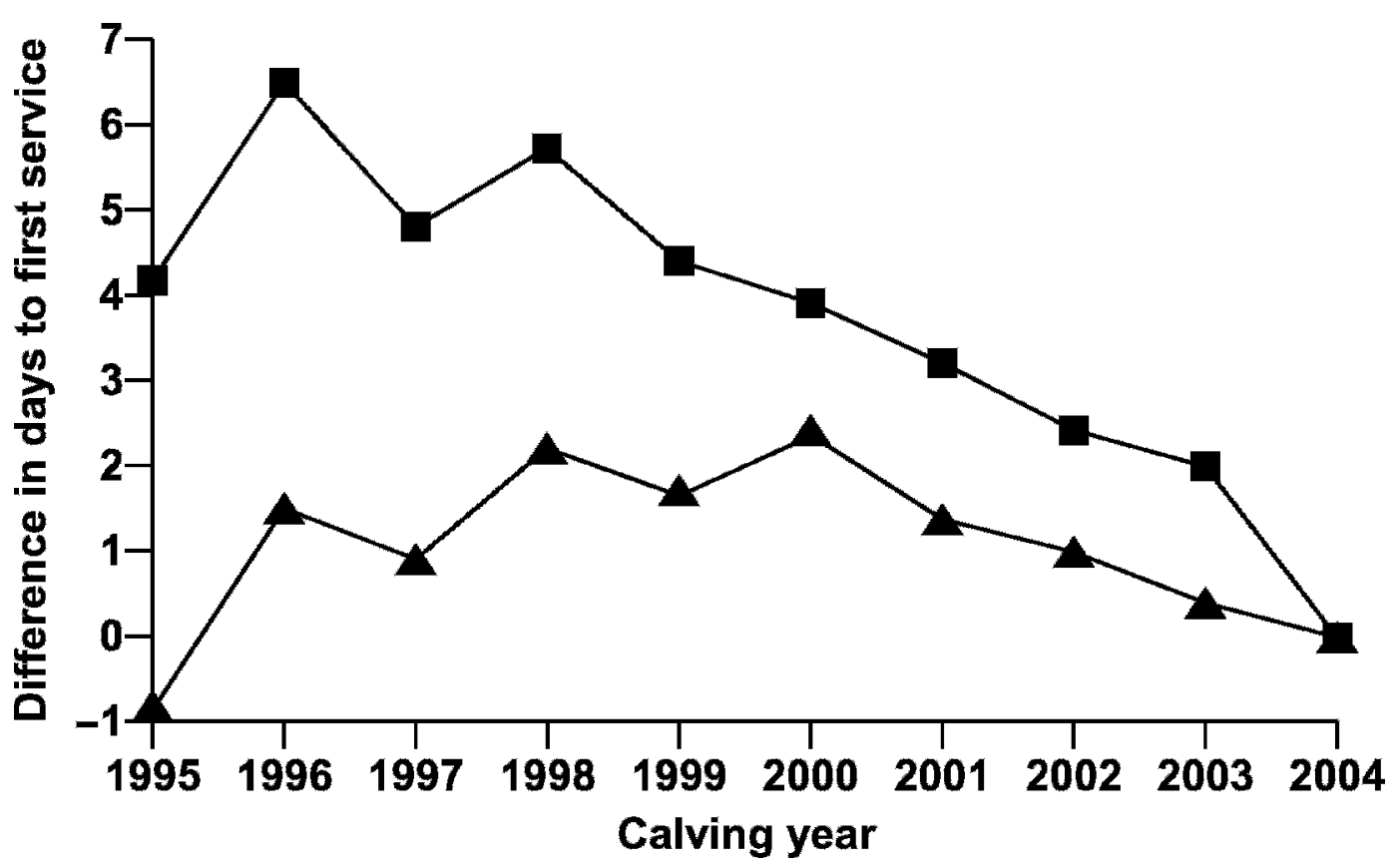

Figure 1. Least squares estimates of difference in days to first service after calving by calving year relative to 2004 for Holsteins ( $\square$ ) and Jerseys $(\mathbf{\Lambda})$.

daughter pregnancy rate (VanRaden et al., 2004) is conservative, because $66 \%$ of herds had $10 \%$ of cows first inseminated by $60 \mathrm{~d}$ in 2005 . The median interval to reach $10 \%$ of cows first inseminated was $55.5 \mathrm{~d}$.
Based on yearly means, intraclass correlations were 0.61 for DFS and 0.48 for number of services. Thus, DFS was somewhat more consistent over time than was number of services, which is less under manage-

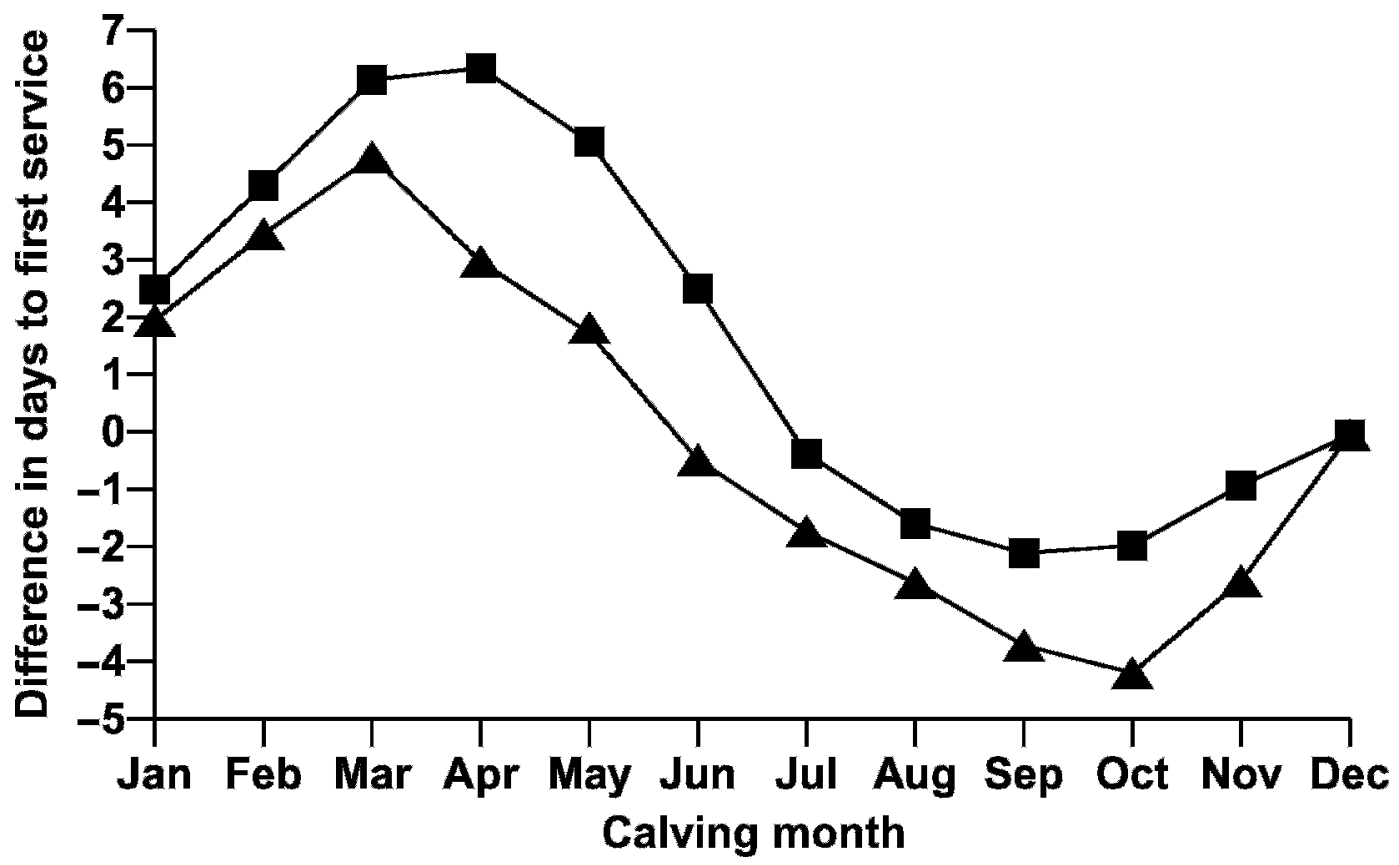

Figure 2. Least squares estimates of difference in days to first service after calving by calving month relative to December Holsteins $(\boldsymbol{\square})$ and Jerseys $(\boldsymbol{\Delta})$. 


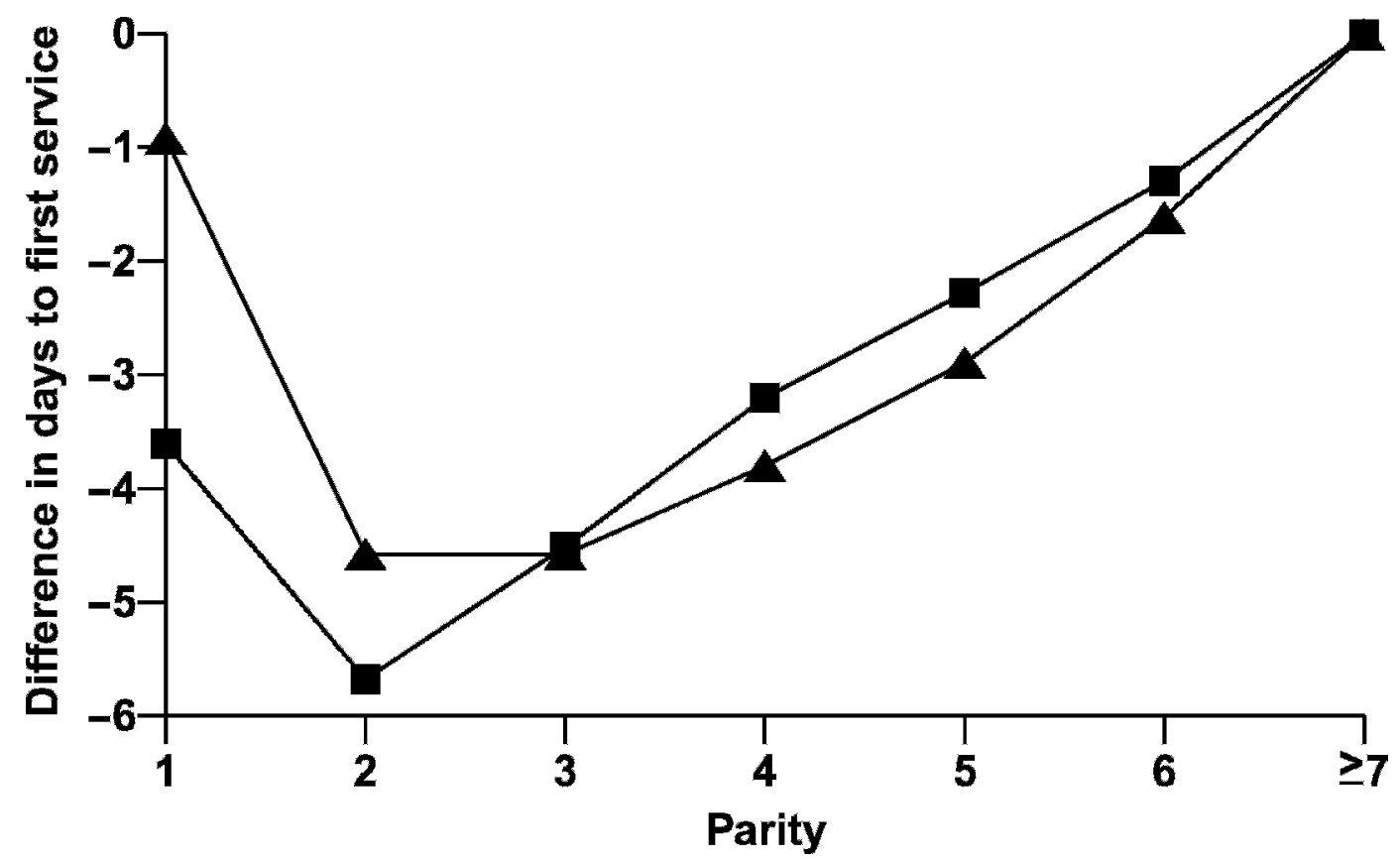

Figure 3. Least squares estimates of difference in days to first service after calving by parity relative to parities $\geq 7$ for Holsteins ( and Jerseys $(\boldsymbol{\Delta})$.

ment control. The correlation of 0.61 for DFS indicates that regardless of the VWP goal that is set for a herd, actual DFS is still subject to large variation because of either management decisions or poor detection of estrus.

\section{Identification of Herds Having Synchronized Breeding}

Herd-years that were classified as not having synchronized breeding were assumed to be practicing tra-

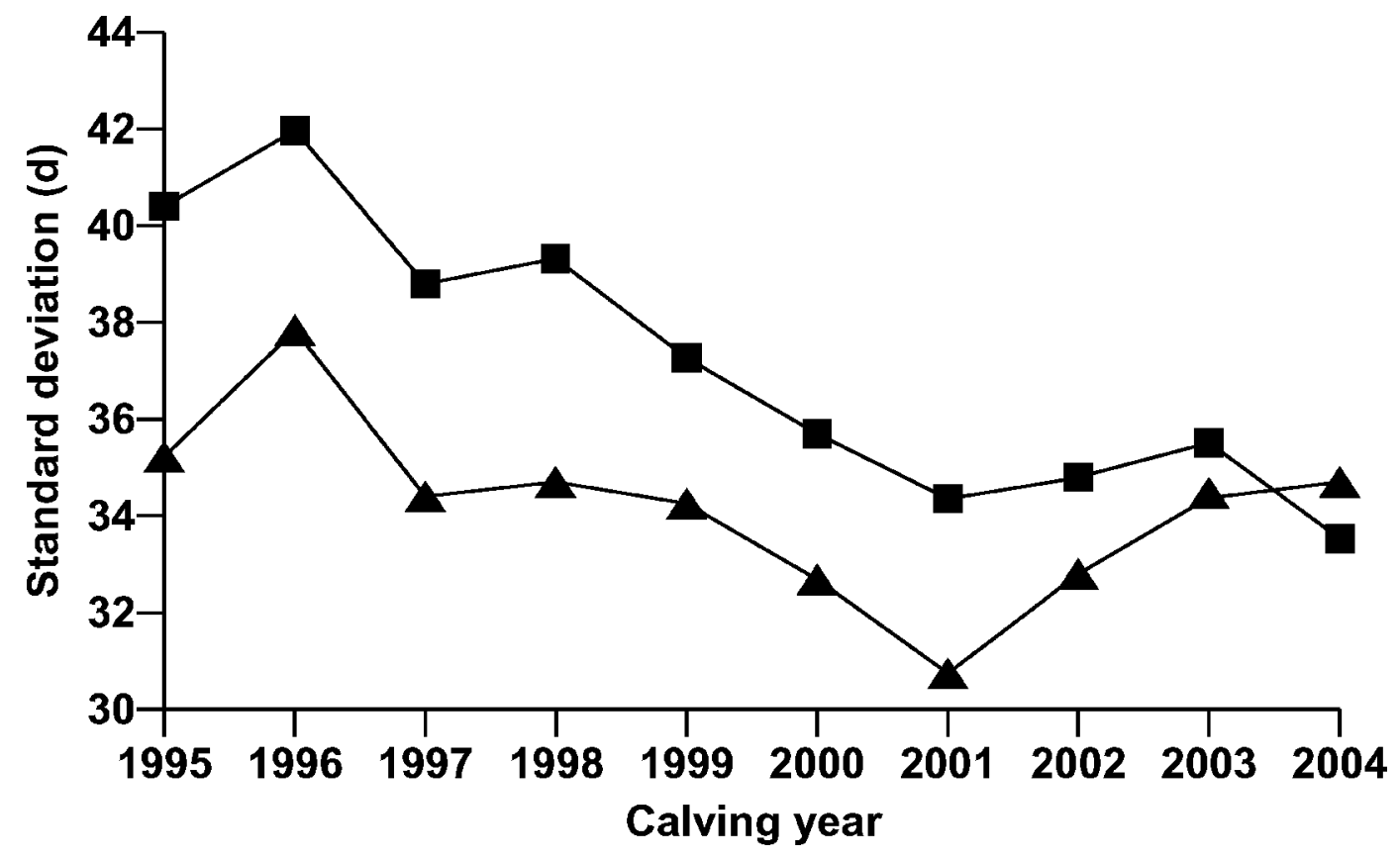

Figure 4. Standard deviations of days to first service after calving by calving year for Holsteins (ロ) and Jerseys (ム). 
Table 3. Cumulative percentages of herd-years and cows with $10 \%$ of cows first inseminated by selected days postpartum for 1995,2000 , and 2005

\begin{tabular}{|c|c|c|c|c|c|c|}
\hline \multirow{2}{*}{$\begin{array}{l}\text { Days } \\
\text { postpartum }\end{array}$} & \multicolumn{2}{|c|}{1995} & \multicolumn{2}{|c|}{2000} & \multicolumn{2}{|c|}{2005} \\
\hline & Herds & Cows & Herds & Cows & Herds & Cows \\
\hline$<30$ & 0 & 0 & 0 & 0 & 0 & 0 \\
\hline$<40$ & 4 & 4 & 5 & 5 & 5 & 4 \\
\hline$<50$ & 28 & 29 & 29 & 36 & 25 & 26 \\
\hline$<60$ & 74 & 77 & 71 & 78 & 66 & 71 \\
\hline$<70$ & 95 & 96 & 92 & 95 & 89 & 93 \\
\hline$<90$ & 100 & 100 & 99 & 99 & 99 & 99 \\
\hline
\end{tabular}

ditional insemination after observed estrus. Herds that were classified as having definite synchronized breeding characteristically had no inseminations recorded on $\geq 1$ specific day of the week during the entire year. Herd-years that were classified as having probable synchronized breeding may include herds that were in the process of changing from one breeding regimen to another or perhaps may have multiple breeding strategies used simultaneously. Further examination of the herds that were classified as definitely synchronizing showed that those herds often changed classification status from definitely to probably synchronizing. The $\bar{\chi}_{h}^{2}$ for those herds often was below the arbitrary minimum $\bar{\chi}_{h}^{2}$ of 400 in subsequent years. Herds that were classified as definitely synchronizing seldom were classified later as not synchronizing. Several explanations could account for herd-years with possible synchronized breeding: synchronized breeding for only a portion of the year or distribution of services across days affected by factors other than synchronization, such as avoidance of Sunday inseminations. For herds classified as not synchronizing breeding, the frequency of Sunday inseminations was slightly less than one-seventh.

Mean herd size differed greatly among the synchronization categories: 87 cows per herd for no synchronization, 117 for possible synchronization, 153 for probable synchronization, and 199 for synchronized breeding. Synchronization protocols are more likely to be adopted for large herds, and detection of estrus may be less of a challenge in small herds. Because of the larger herd sizes for herds with probable and definite synchronized breedings, the increase in the number of cows that receive hormonal intervention would be much greater than the increase in the number of herds.

Preliminary analysis with only a mean $\chi^{2}$ statistic indicated a lack of sensitivity for small herds, for which the expected number of inseminations per day could be small. Accuracy of synchronization identification was improved for small herds by requiring minimums for both $\%_{\max }$ and $\bar{\chi}_{h}^{2}$ (see Appendix). Limiting herd size to $\geq 50$ cows would likely increase accuracy of classification. The identification method also may not be effective for extremely large herds, which may have many cow groups formed for synchronization and TAI protocols performed on different days of the week.

A further complication in describing management regimens is that second inseminations may not follow the same protocol used for first inseminations. When the identification method was applied to second inseminations, only half as many herds were classified as having definite or probable synchronization compared with first inseminations. A more complete description of management regimens might include classification of both first and second inseminations.

\section{Trend in the Use of Synchronized Breeding}

Overall herd-year frequencies for the 4 synchronization categories were $84 \%$ for no synchronized breeding, $6 \%$ for possible synchronized breeding, $9 \%$ for probable synchronized breeding, and $1 \%$ for synchronized breeding. Figure 5 shows the frequencies of the 4 synchronization categories for first inseminations in 1996, 2000, and 2005. No herd-years in 1996 were classified as definitely having synchronized breeding, but $2.3 \%$ of herd-years in 2005 were classified as definitely synchronized. When the categories for probable and definite synchronization were combined, frequency of herd-years increased from $1.9 \%$ in 1996 to $19.9 \%$ in 2005. Frequency of cows in synchronized herds increased from 2 to $35 \%$ between 1996 and 2005.

\section{Effect of Synchronized Breeding on DFS, Number of Services, and Days Open}

Least squares estimates of differences in DFS and number of services because of synchronized breeding are in Table 4. Use of synchronized breeding resulted in a substantial reduction in DFS as reported by Pursley et al. (1997a). Compared with herd-years with no synchronized breeding, herd-years that were classified as having synchronized breeding had 17.0 fewer DFS, 


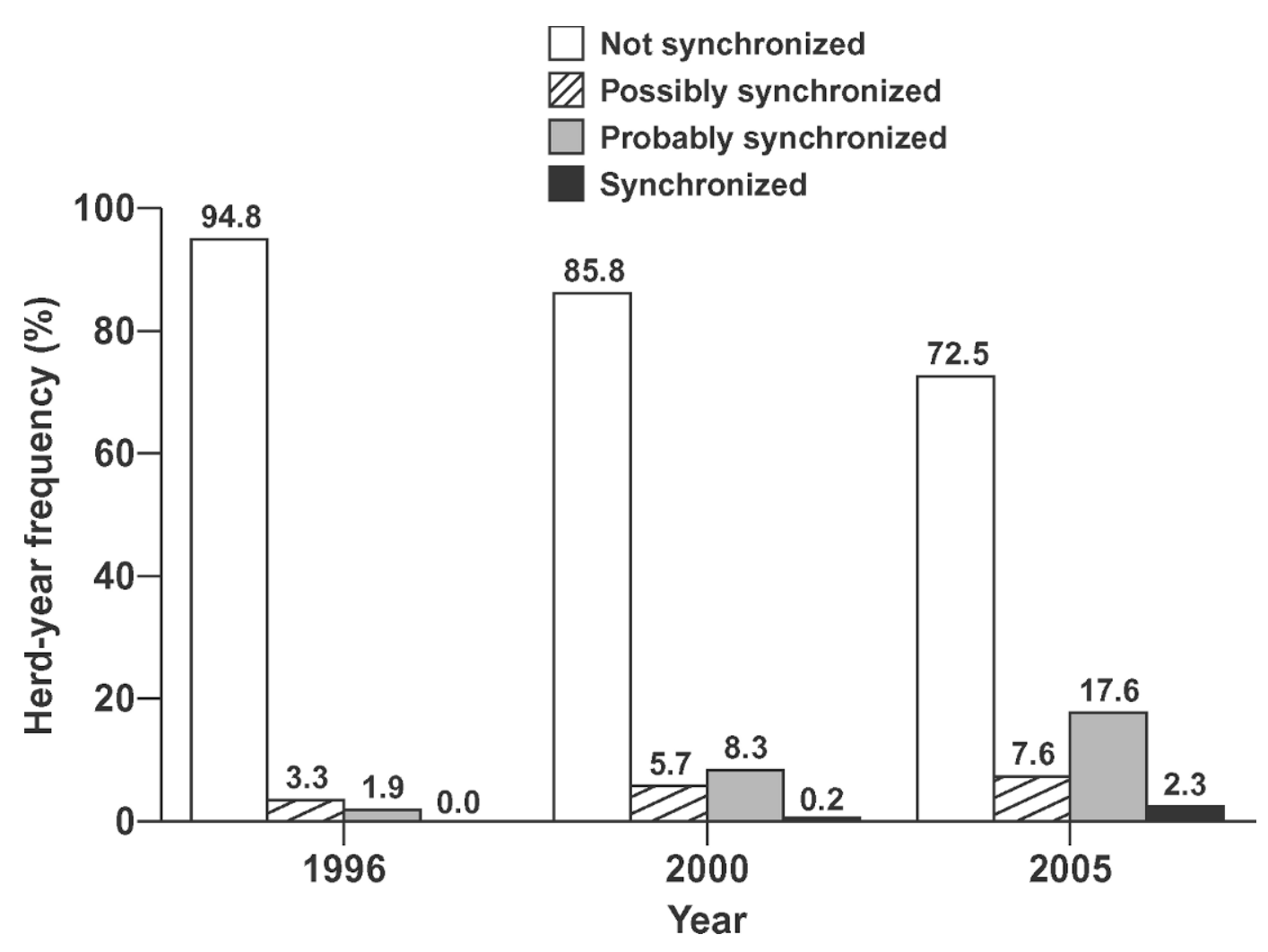

Figure 5. Percentage of herd-years by synchronized breeding status as determined by $\chi^{2}$ analysis based on frequency of first inseminations by day of the week and maximum percentage inseminated on 1 day of the week for 1996, 2000, and 2005.

herd-years with probable synchronization had $9.3 \mathrm{~d}$ fewer, and possibly synchronized herd-years had 3.3 $\mathrm{d}$ fewer. In agreement with the results of Tenhagen et al. (2003), additional semen was used by herd-years with synchronized breeding ( 0.16 services/cow) compared with herd-years without synchronized breeding.

Days open is a key criterion for comparing economic usefulness of alternative reproductive management regimens. Least squares estimates of differences in days open because of synchronized breeding are in Table 4. Cows in herd-years with synchronized breeding were open $9.1 \mathrm{~d}$ fewer than were cows in herdyears with no synchronized breeding, which was about half of what Goodling et al. (2005) reported. Only slightly more than $50 \%$ of the reduction in DFS (17 d) for herd-years with synchronized breeding was realized in reduced days open. Days open for possibly synchronized herd-years were similar (difference of $<1 \mathrm{~d}$ ) to those for herd-years without synchronization. Herdyears with probable synchronization were intermediate for days open (difference of $4.5 \mathrm{~d}$ ) to herd-years with and without synchronized breeding.

\section{CONCLUSIONS}

Calving month, calving year, and parity all had large effects on DFS for both Holsteins and Jerseys. Holstein

Table 4. Least squares estimates of within-herd differences in days to first service after calving, number of services, and days open because of synchronized breeding

\begin{tabular}{lccc}
\hline $\begin{array}{l}\text { Herd-year status for } \\
\text { synchronized breeding }^{1}\end{array}$ & $\begin{array}{c}\text { Days to first service } \\
(\mathrm{n}=61,921)\end{array}$ & $\begin{array}{c}\text { Services } \\
(\mathrm{n}=61,524)\end{array}$ & $\begin{array}{c}\text { Days open } \\
(\mathrm{n}=61,921)\end{array}$ \\
\hline None & 0.0 & 0.00 & 0.0 \\
Possible & -3.3 & 0.06 & -0.7 \\
Probable & -9.3 & 0.11 & -4.5 \\
Synchronized & -17.0 & 0.16 & -9.1 \\
\hline
\end{tabular}

${ }^{1}$ Synchronized breeding status of herd-years as determined by $\chi^{2}$ analysis based on frequency of first inseminations by day of the week and maximum percentage inseminated on $1 \mathrm{~d}$ of the week. 
cows that calved during March and April were bred later than cows that calved during other months, whereas Jersey cows that calved during February and March were bred later. For both breeds, cows that calved during September and October were bred earlier. First-parity cows were bred later than secondparity cows, especially for Jerseys.

The VWP of a herd was measured as the postpartum interval in which $10 \%$ of cows had been first inseminated. The percentage of herds with $10 \%$ of cows first inseminated by $60 \mathrm{~d}$ postpartum decreased from 74 in 1995 to 66 in 2005.

Adoption of synchronized breeding as determined from analysis of frequency of first services by day of the week has increased steadily from $1.9 \%$ of herdyears (2\% of cows) in 1996 to $19.9 \%$ of herd-years (35\% of cows) in 2005. Those percentages, however, are affected greatly by how herd status for synchronized breeding is defined and may not represent national use of synchronized breeding, especially because data were not nationwide. Because of the reductions in DFS $(17 \mathrm{~d})$ and days open $(9.1 \mathrm{~d})$ in synchronized breeding regimens, the adoption of synchronized breeding may partly explain the decrease in DFS in later years. Those reductions, however, may reflect an enhanced ability to achieve desired VWP rather than a change in desired VWP. The standard deviation of DFS of herds that were classified as definitely synchronized was only 0.38 that of herds that were bred based on observed estrus.

Although further refinement of the method to determine herd status for synchronized breeding may be possible, that method might be used to identify herds with large or extremely small likelihoods of synchronized breeding. Data from those herds can be analyzed to determine if reproductive management of herds should be considered in genetic evaluations of daughter pregnancy rate. Days open may be a different trait in herds with synchronized breeding compared with herds with traditional detection of estrus. The genetic correlation between days open for those 2 reproductive management regimens should be determined. If the genetic correlation is $<1.0$, evaluation procedures may need to be modified. Variance heterogeneity should also be investigated.

\section{ACKNOWLEDGMENTS}

The cooperation of AgriTech Analytics (Visalia, CA), AgSource Cooperative Services (Verona, WI), Dairy Records Management Systems (Raleigh, NC), DHI Computing Services (Provo, UT), and Texas DHIA (College Station, TX) in supplying yield data through the national Genetic Evaluation Program was invalu- able. The assistance of S. M. Hubbard and J. R. Wright, Animal Improvement Programs Laboratory (Beltsville, MD), in manuscript review is appreciated as well as comments and suggestions by 2 anonymous Journal of Dairy Science reviewers, which resulted in an improved manuscript.

\section{REFERENCES}

Animal Improvement Programs Laboratory. 2006. Trend in DPR breeding values for Holstein. http://aipl.arsusda.gov/eval/ summary/trend.cfm?trnd_tbl=HOd Accessed July 25, 2006.

Britt, J. H. 1975. Early postpartum breeding in dairy cows: A review. J. Dairy Sci. 58:266-271.

Faust, M. A., B. T. McDaniel, O. W. Robison, and J. H. Britt. 1988 Environmental and yield effects on reproduction in primiparous Holsteins. J. Dairy Sci. 71:3092-3099.

Goodling, R. C., Jr., G. E. Shook, K. A. Weigel, and N. R. Zwald. 2005. The effect of synchronization on genetic parameters of reproductive traits in dairy cattle. J. Dairy Sci. 88:2217-2225.

Harrison, R. O., S. P. Ford, J. W. Young, A. J. Conley, and A. E. Freeman. 1990. Increased milk production versus reproductive and energy status of high producing cows. J. Dairy Sci. 73:2749-2758.

Linderoth, S. 2005. Don't cheat on your voluntary waiting period. Dairy Herd Management 42(2):32-35.

Miller, R. H., H. D. Norman, M. T. Kuhn, and J. S. Clay. 2005. Assessment of voluntary waiting period and frequency of estrus synchronization among herds. J. Dairy Sci. 88(Suppl. 1):301. (Abstr.)

Moreira, F., C. Risco, M. F. A. Pires, J. D. Ambrose, M. Drost, M. DeLorenzo, and W. W. Thatcher. 2000. Effect of body condition on reproductive efficiency of lactating dairy cows receiving a timed insemination. Theriogenology 53:1305-1319.

Olson, J. 2004. Optimal VWP for first lactation cows. Pfizer, Inc., GCA04003. http://www.100daycontract.com/pdf/Optimal_ VWP_For_First_Lactation_Cows.pdf Accessed July 12, 2006.

Plunkett, S. S., J. S. Stevenson, and E. P. Call. 1984. Prostaglandin $\mathrm{F}_{2 \alpha}$ for lactating dairy cows with a palpable corpus luteum but unobserved estrus. J. Dairy Sci. 67:380-387.

Pursley, J. R., M. R. Kosorok, and M. C. Wiltbank. 1997a. Reproductive management of lactating dairy cows using synchronization of ovulation. J. Dairy Sci. 80:301-306.

Pursley, J. R., M. O. Mee, and M. C. Wiltbank. 1995. Synchronization of ovulation in dairy cows using $\mathrm{PGF}_{2 \alpha}$ and GnRH. Theriogenology 44:915-923.

Pursley, J. R., M. C. Wiltbank, J. S. Stevenson, J. S. Ottobre, H. A. Garverick, and L. L. Anderson. 1997b. Pregnancy rates per artificial insemination for cows and heifers inseminated at a synchronized ovulation or synchronized estrus. J. Dairy Sci. 80:295-300.

Rabiee, A. R., I. J. Lean, and M. A. Stevenson. 2005. Efficacy of Ovsynch program on reproductive performance in dairy cattle: A meta-analysis. J. Dairy Sci. 88:2754-2770.

Stevenson, J. S. 2004. To Ovsynch or not to Ovsynch. Hoard's Dairyman 149:734-735.

Stevenson, J. S. 2005. Have we come full circle? Hoard's Dairyman 150:199.

Stevenson, J. S., and A. P. Phatak. 2005. Inseminations at estrus induced by presynchronization before application of synchronized estrus and ovulation. J. Dairy Sci. 88:399-405.

Tenhagen, B.-A., M. Drillich, and W. Heuwieser. 2001. Analysis of cow factors influencing conception rates after two timed breeding protocols. Theriogenology 56:831-838.

Tenhagen, B.-A., M. Drillich, R. Surholt, and W. Heuwieser. 2004. Comparison of timed AI after synchronized ovulation to AI at estrus: Reproductive and economic considerations. J. Dairy Sci. 87:85-94. 
Tenhagen, B.-A., C. Vogel, M. Drillich, G. Thiele, and W. Heuwieser. 2003. Influence of stage of lactation and milk production on conception rates after timed artificial insemination following Ovsynch. Theriogenology 60:1527-1537.

VanRaden, P. M., A. H. Sanders, M. E. Tooker, R. H. Miller, H. D. Norman, M. T. Kuhn, and G. R. Wiggans. 2004. Development of a national genetic evaluation for cow fertility. J. Dairy Sci. 87:2285-2292.

Washburn, S. P., W. J. Silvia, C. H. Brown, B. T. McDaniel, and A. J. McAllister. 2002. Trends in reproductive performance in Southeastern Holstein and Jersey DHI herds. J. Dairy Sci. 85:244-251.

Weller, J. I., and Y. Folman. 1990. Effects of calf value and reproductive management on optimum days to first breeding. J. Dairy Sci. 73:1318-1326.

Williamson, N. B., F. W. Quinton, and G. A. Anderson. 1980. The effect of variations in the interval between calving and first service on the reproductive performance of normal dairy cows. Aust. Vet. J. 56:477-480.

\section{APPENDIX}

Simulated distributions of first inseminations across days of the week were used to determine the effectiveness of $\%_{\max }$ and $\bar{\chi}_{h}^{2}$ to detect accurately unequal distributions of inseminations. First, minimum values of

$\%_{\max }$ and $\bar{\chi}_{h}^{2}$ that could serve as indicators of synchro- nized breeding were determined. A second independent analysis applied those criteria to the simulated data to designate herd synchronization status, and then error rates were assessed.

Goodling et al. (2005) suggested that dairy producers might follow different breeding practices when using synchronization. For example, scheduled insemination only (TAI), synchronized estrus with insemination after observed estrus, synchronization only for cows for which estrus detection is difficult, and so on. Those practices would lead to variable insemination distributions by day of the week even when synchronization was being used. For example, using only TAI would lead to nearly all inseminations on the same day of the week, whereas synchronized estrus followed by insemination on observed estrus could lead to varied insemination distributions by day of the week. Therefore, 10,000 replicates (herds) with random assignment of inseminations based on 10 first-insemination distributions (Table A1) were simulated for 7 herd sizes $(30,50,100,300,500,1,000$, and 3,000 cows), which resulted in 700,000 observations. Insemination distribution 1 had the most extreme probability fre-

Table A1. Simulated distributions (probability of occurrence) of first inseminations by day of the week

\begin{tabular}{lccccccr}
\hline \multirow{2}{*}{$\begin{array}{l}\text { Insemination } \\
\text { distribution }\end{array}$} & \multicolumn{7}{c}{ Day of the week, \% } \\
\cline { 2 - 7 } & 1 & 2 & 3 & \multicolumn{1}{c}{4} & \multicolumn{1}{c}{5} & \multicolumn{1}{c}{6} & 7 \\
\hline 1 & 0.00 & 0.00 & 0.00 & 100.00 & 0.00 & 0.00 & 0.00 \\
2 & 0.00 & 0.00 & 5.00 & 90.00 & 5.00 & 0.00 & 0.00 \\
3 & 0.00 & 2.50 & 7.50 & 80.00 & 7.50 & 2.50 & 0.00 \\
4 & 2.50 & 5.00 & 7.50 & 70.00 & 7.50 & 5.00 & 2.50 \\
5 & 5.00 & 5.00 & 5.00 & 70.00 & 5.00 & 5.00 & 5.00 \\
6 & 5.00 & 6.00 & 9.00 & 60.00 & 9.00 & 6.00 & 5.00 \\
7 & 6.67 & 6.67 & 6.67 & 60.00 & 6.67 & 6.67 & 6.67 \\
8 & 7.00 & 8.00 & 10.00 & 50.00 & 10.00 & 8.00 & 7.00 \\
9 & 8.33 & 8.33 & 8.33 & 50.00 & 8.33 & 8.33 & 8.33 \\
10 & 14.29 & 14.29 & 14.29 & 14.29 & 14.29 & 14.29 & 14.29 \\
\hline
\end{tabular}

Table A2. Means, minimums, and maximums for maximum percentage of first inseminations on $1 \mathrm{~d}$ of the week $\left(\%_{\max }\right)$ and mean $\chi^{2}$ adjusted for herd size $\left(\bar{\chi}_{h}^{2}\right)$ by insemination distribution for simulated data across herds

\begin{tabular}{|c|c|c|c|c|c|c|}
\hline \multirow{2}{*}{$\begin{array}{l}\text { Insemination } \\
\text { distribution }^{1}\end{array}$} & \multicolumn{3}{|c|}{$\%_{\max }$} & \multicolumn{3}{|c|}{$\bar{\chi}_{h}^{2}$} \\
\hline & Mean & Minimum & Maximum & Mean & Minimum & Maximum \\
\hline 1 & 100 & 100 & 100 & 600 & 600 & 600 \\
\hline 2 & 90 & 79 & 96 & 472 & 357 & 553 \\
\hline 3 & 80 & 67 & 90 & 359 & 245 & 477 \\
\hline 4 & 70 & 54 & 83 & 259 & 146 & 398 \\
\hline 5 & 70 & 55 & 83 & 257 & 147 & 393 \\
\hline 6 & 60 & 44 & 74 & 176 & 89 & 303 \\
\hline 7 & 60 & 44 & 75 & 175 & 84 & 305 \\
\hline 8 & 50 & 34 & 66 & 110 & 43 & 227 \\
\hline 9 & 50 & 35 & 67 & 109 & 47 & 237 \\
\hline 10 & 19 & 15 & 29 & 6 & $<1$ & 35 \\
\hline
\end{tabular}

${ }^{1}$ Distribution of simulated first inseminations by day of the week as defined in Table A1. 
Table A3. Means, minimums, and maximums for maximum percentage of first inseminations on $1 \mathrm{~d}$ of the week $\left(\%_{\max }\right)$ and mean $\chi^{2}$ adjusted for herd size $\left(\bar{\chi}_{h}^{2}\right)$ by insemination distribution and herd size for simulated data

\begin{tabular}{|c|c|c|c|c|c|c|c|}
\hline \multirow{2}{*}{$\begin{array}{l}\text { Insemination } \\
\text { distribution }^{1}\end{array}$} & \multirow{2}{*}{$\begin{array}{c}\text { Herd } \\
\text { size }\end{array}$} & \multicolumn{3}{|c|}{$\%_{\max }$} & \multicolumn{3}{|c|}{$\bar{\chi}_{h}^{2}$} \\
\hline & & Mean & Minimum & Maximum & Mean & Minimum & Maximum \\
\hline \multirow[t]{7}{*}{2} & 30 & 90 & 60 & 100 & 475 & 210 & 600 \\
\hline & 50 & 90 & 72 & 100 & 474 & 291 & 600 \\
\hline & 100 & 90 & 77 & 99 & 472 & 334 & 586 \\
\hline & 300 & 90 & 82 & 96 & 471 & 383 & 541 \\
\hline & 500 & 90 & 84 & 95 & 471 & 403 & 528 \\
\hline & 1,000 & 90 & 87 & 94 & 471 & 432 & 519 \\
\hline & 3,000 & 90 & 88 & 92 & 470 & 446 & 494 \\
\hline \multirow[t]{7}{*}{3} & 30 & 80 & 50 & 100 & 364 & 130 & 600 \\
\hline & 50 & 80 & 60 & 98 & 362 & 185 & 573 \\
\hline & 100 & 80 & 63 & 93 & 360 & 213 & 506 \\
\hline & 300 & 80 & 71 & 88 & 358 & 270 & 442 \\
\hline & 500 & 80 & 73 & 86 & 357 & 289 & 427 \\
\hline & 1,000 & 80 & 75 & 85 & 357 & 305 & 406 \\
\hline & 3,000 & 80 & 77 & 83 & 357 & 325 & 387 \\
\hline \multirow[t]{7}{*}{4} & 30 & 70 & 40 & 97 & 267 & 60 & 555 \\
\hline & 50 & 70 & 38 & 92 & 262 & 69 & 494 \\
\hline & 100 & 70 & 49 & 89 & 259 & 107 & 458 \\
\hline & 300 & 70 & 60 & 79 & 256 & 175 & 340 \\
\hline & 500 & 70 & 61 & 78 & 256 & 185 & 332 \\
\hline & 1,000 & 70 & 64 & 77 & 256 & 208 & 319 \\
\hline & 3,000 & 70 & 66 & 73 & 255 & 218 & 286 \\
\hline \multirow[t]{7}{*}{5} & 30 & 70 & 37 & 97 & 266 & 54 & 555 \\
\hline & 50 & 70 & 42 & 92 & 260 & 70 & 494 \\
\hline & 100 & 70 & 50 & 86 & 256 & 110 & 421 \\
\hline & 300 & 70 & 60 & 81 & 255 & 174 & 364 \\
\hline & 500 & 70 & 63 & 77 & 254 & 194 & 324 \\
\hline & 1,000 & 70 & 64 & 76 & 253 & 204 & 306 \\
\hline & 3,000 & 70 & 66 & 74 & 254 & 222 & 287 \\
\hline \multirow[t]{7}{*}{6} & 30 & 60 & 27 & 90 & 186 & 31 & 471 \\
\hline & 50 & 60 & 32 & 84 & 180 & 33 & 400 \\
\hline & 100 & 60 & 41 & 77 & 176 & 60 & 323 \\
\hline & 300 & 60 & 49 & 72 & 173 & 99 & 270 \\
\hline & 500 & 60 & 52 & 68 & 173 & 118 & 235 \\
\hline & 1,000 & 60 & 54 & 66 & 172 & 133 & 222 \\
\hline & 3,000 & 60 & 57 & 63 & 172 & 149 & 198 \\
\hline \multirow[t]{7}{*}{7} & 30 & 60 & 27 & 90 & 184 & 23 & 469 \\
\hline & 50 & 60 & 30 & 86 & 180 & 28 & 422 \\
\hline & 100 & 60 & 39 & 78 & 175 & 52 & 332 \\
\hline & 300 & 60 & 50 & 71 & 172 & 103 & 263 \\
\hline & 500 & 60 & 49 & 68 & 171 & 101 & 239 \\
\hline & 1,000 & 60 & 54 & 66 & 171 & 132 & 215 \\
\hline & 3,000 & 60 & 57 & 63 & 171 & 147 & 196 \\
\hline \multirow[t]{7}{*}{8} & 30 & 50 & 20 & 83 & 121 & 6 & 395 \\
\hline & 50 & 50 & 22 & 80 & 115 & 14 & 356 \\
\hline & 100 & 50 & 31 & 67 & 110 & 26 & 230 \\
\hline & 300 & 50 & 36 & 61 & 106 & 39 & 178 \\
\hline & 500 & 50 & 42 & 59 & 106 & 64 & 165 \\
\hline & 1,000 & 50 & 43 & 56 & 105 & 71 & 141 \\
\hline & 3,000 & 50 & 46 & 54 & 105 & 85 & 127 \\
\hline \multirow{7}{*}{9} & 30 & 50 & 20 & 90 & 121 & 7 & 471 \\
\hline & 50 & 50 & 22 & 76 & 114 & 16 & 316 \\
\hline & 100 & 50 & 33 & 70 & 110 & 29 & 256 \\
\hline & 300 & 50 & 40 & 62 & 106 & 58 & 184 \\
\hline & 500 & 50 & 41 & 59 & 105 & 61 & 161 \\
\hline & 1,000 & 50 & 44 & 57 & 105 & 73 & 146 \\
\hline & 3,000 & 50 & 46 & 53 & 104 & 85 & 125 \\
\hline \multirow[t]{7}{*}{10} & 30 & 24 & 17 & 47 & 20 & 1 & 113 \\
\hline & 50 & 22 & 16 & 44 & 12 & $<1$ & 79 \\
\hline & 100 & 20 & 15 & 32 & 6 & $<1$ & 32 \\
\hline & 300 & 17 & 15 & 23 & 2 & $<1$ & 9 \\
\hline & 500 & 17 & 15 & 21 & 1 & 0 & 6 \\
\hline & 1,000 & 16 & 15 & 19 & 1 & 0 & 2 \\
\hline & 3,000 & 15 & 14 & 17 & $<1$ & 0 & $<1$ \\
\hline
\end{tabular}

${ }^{1}$ Distribution of simulated first inseminations by day of the week as defined in Table A1. Mean, minimum, and maximum $\%_{\max }$ and $\bar{\chi}_{h}^{2}$ are in Table A2 for insemination distribution 1 (all inseminations on the same day). 
quency among 9 synchronization distributions (100\% of inseminations on $1 \mathrm{~d}$ of the week), and insemination distribution 10 represented no herd synchronization (equal distribution across days of the week). Herd size was included as a variable because 1) deviations from expected distributions are more likely to occur in smaller herds and 2) preliminary analysis indicated that $\bar{\chi}_{h}^{2}$ was slightly correlated $(-0.012)$ with herd size.

Based on the simulated data, the mean, minimum, and maximum were calculated for $\%_{\max }$ and $\bar{\chi}_{h}^{2}$ across herd sizes (Table A2) as well as for each combination of herd size and insemination distribution (Table A3); frequency distributions (not shown) also were calculated for $\%_{\max }$ and $\bar{\chi}_{h}^{2}$. Those summary statistics were examined to identify levels that would function well as minimums for identifying herds with or without synchronized breeding. In particular, results for the insemination distribution that indicated no synchronization (all days with equal probability of insemination) were compared with results for other insemination distributions, which represented various unequal probabilities of breedings across days (synchronization). For example, if mean $\bar{\chi}_{h}^{2}$ was 10 for the equal distribution of inseminations over the week and the smallest mean for other insemination distributions was 100 , then a $\bar{\chi}_{h}^{2}$ of $>10$ but $<100$ could be used to designate herds as having synchronized breeding. The minimums, maximums, and frequency distributions (variation in $\%_{\max }$ and $\bar{\chi}_{h}^{2}$ ) would then help to narrow further the range for effective minimums.

Of the simulated distributions for synchronized breedings (1 through 9), the mean was smallest for distributions 8 and 9 for $\%_{\max }$ and for distribution 9 for $\bar{\chi}_{h}^{2}$ (Table A2). Both means were considerably larger than those for distribution 10 (the simulation for no synchronization with inseminations on all days equally likely), which indicates that herds with synchronized breeding could be identified effectively with either or both statistics. Based on minimums and maximums in Table A3, a requirement that $\bar{\chi}_{h}^{2}$ be $>100$ would result in misidentification of some 30-, 50-, 100-, and even 300-cow herds with synchronization as herds without synchronization. Examination of the frequency distributions (not shown) as well as the minimums and maximums in Table A3 indicated that only a few synchronizing herds would be missed with a $\bar{\chi}_{h}^{2}$ minimum of 40 . Likewise, although a few nonsynchronizing herds had a $\bar{\chi}_{h}^{2}$ of $>40$ (Table A3), only a few herds would be categorized as synchronizing when they were not. A similar examination for $\%_{\max }$ indicated that a minimum in the range of 30 to 40 would
Table A4. Percentage of herds with correct synchronization status assigned and percentages of type I and II errors for simulated data by identification criteria

\begin{tabular}{lccc}
\hline & \multirow{2}{*}{$\begin{array}{c}\text { Correct } \\
\text { identification } \\
(\%)\end{array}$} & \multicolumn{2}{c}{ Error $^{2}(\%)$} \\
\cline { 3 - 4 } Criterion $^{1}$ & 99.78 & Type I & Type II \\
\hline 1 & 99.78 & 0.050 & 0.17 \\
2 & 99.76 & 0.023 & 0.20 \\
3 & 99.79 & 0.021 & 0.21 \\
4 & & 0.050 & 0.15 \\
\hline
\end{tabular}

${ }^{1}$ Criteria: $1=$ minimum for mean $\chi^{2}$ adjusted for herd size $\left(\bar{\chi}_{h}^{2}\right)$ only; $2=$ minimum for maximum percentage of first inseminations on $1 \mathrm{~d}$ of the week ( $\left.\%_{\max }\right)$ only; $3=$ minimums for both $\bar{\chi}_{h}^{2}$ and $\%_{\max }$; and $4=$ minimum for either $\bar{\chi}_{h}^{2}$ or $\%_{\max }$.

${ }^{2}$ Type I error = herd designated as synchronizing when it was not; type II error = herd designated as not synchronizing when it was.

be effective for identifying herds as synchronizing if they had a $\%_{\max }$ above the minimum.

In a second analysis, 4 general criteria were tested for their effectiveness in identifying synchronization: 1) requiring a herd to meet a minimum for $\bar{\chi}_{h}^{2}$ only, 2) requiring a herd to meet a minimum for $\%_{\max }$ only, 3) requiring a herd to meet minimums for both $\bar{\chi}_{h}^{2}$ and $\%_{\max }$, and 4) requiring a herd to meet a minimum for either $\bar{\chi}_{h}^{2}$ or $\%_{\max }$. The percentages of correct and incorrect assignments were calculated for each of the 4 identification criteria. Incorrect assignments were further classified by type of error: type I (herd designated as synchronizing when it was not) or type II (failure to designate a herd as synchronizing when it was as indicated by an insemination distribution that was not equal over days of the week). Overall percentage of correct classifications as well as type I and II error rates for each of the 4 criteria are shown in Table A4. All 4 criteria had extremely low error rates; the smallest overall percentage of correct classifications

Table A5. Percentage of herds with correct synchronization status assigned and percentages of type I and II errors based on criterion $3^{1}$ for simulated data by herd size

\begin{tabular}{lccc}
\hline \multirow{2}{*}{$\begin{array}{l}\text { Herd } \\
\text { size }\end{array}$} & $\begin{array}{c}\text { Correct } \\
\text { identification } \\
(\%)\end{array}$ & \multicolumn{2}{c}{ Error $^{2}(\%)$} \\
\cline { 3 - 4 } & 98.74 & 0.14 & Type I \\
\hline 30 & 99.65 & 0.01 & 1.12 \\
50 & 99.96 & 0.04 & 0.34 \\
300 & 100.00 & 0.00 & 0.00 \\
500 & 100.00 & 0.00 & 0.00 \\
1,000 & 100.00 & 0.00 & 0.00 \\
3,000 & 100.00 & 0.00 & 0.00 \\
\hline
\end{tabular}

${ }^{1}$ Minimums for both mean $\chi^{2}$ adjusted for herd size and maximum percentage of first inseminations on $1 \mathrm{~d}$ of the week.

${ }^{2}$ Type I error = herd designated as synchronizing when it was not; type II error = herd designated as not synchronizing when it was. 
was $99.76 \%$, which was only 0.02 to 0.03 percentage units less than the other 3 criteria. Table A5 shows error rates for criterion 3 by herd size. All misclassifications occurred in herds with $\leq 100$ cows, with the majority of errors for herds with 30 cows. Furthermore, almost all errors were type II errors; few herds were classified as synchronizing when they were not.

Criterion 3 (require minimums for both $\bar{\chi}_{h}^{2}$ and $\%_{\max }$ ) was chosen as the criterion to apply to actual data. Although the total error rate for criterion 3 was slightly larger than those for the other 3 criteria, it had the smallest overall type I error rate (Table A4). Misclassifying herds as having synchronized breeding when they did not (type I error) was considered to be a more serious problem than missing a herd that did have synchronized breeding (type II error). Although the correlation between $\%_{\max }$ and $\bar{\chi}_{h}^{2}$ was quite large (0.955), the 2 statistics still provided some independent information. Most of the type II errors for criterion 3 occurred because synchronizing herds did not meet the minimum for $\%_{\max }$ rather than for $\bar{\chi}_{h}^{2}$; that is, the herds had a low peak for maximum percentage of first inseminations on $1 \mathrm{~d}$ of the week. Such a situation might occur when synchronization is being used only as a remedial tool for cows for which detection of estrus was difficult. Application of minimums for both $\%_{\max }$ and $\bar{\chi}_{h}^{2}$ to actual data is also appealing because of the many unforeseen anomalies that may occur. One statistic might counteract an unknown identification weakness of the other. For example, if Sunday inseminations were avoided in a large herd that did not have synchronized breeding, then the herd might be misclassified as synchronizing based on $\bar{\chi}_{h}^{2}$ even though $\%_{\max }$ would likely still be too small for the herd to be designated as synchronizing. Preliminary analyses indicated that a minimum of 35 for $\%_{\max }$ regardless of herd size and $\bar{\chi}_{h}^{2}$ minimums of 45 for herds with $<50$ cows and 40 for herds with $\geq 50$ cows optimized the 4 criteria. 